\title{
Factors Affecting the Implementation of Formative Assessment in Some Selected Primary Schools in Nekemte Town, Oromia Region, Ethiopia
}

\author{
Misgana File Bayissa ${ }^{1}$ and Chali Abate Jote ${ }^{2 *}$ \\ ${ }^{1}$ Department of Psychology, Nekemte College of Teacher Education, Ethiopia \\ ${ }^{2}$ Department of Chemistry, Nekemte College of Teacher Education, Ethiopia
}

Submission: September 11, 2019; Published: September 25, 2019

"Corresponding author: Chali Abate Jote, Department of Chemistry, Nekemte College of Teacher Education, P.0.B. 88, Nekemte, Ethiopia

\begin{abstract}
The purpose of the study was to examine factors affecting the implementation of formative assessment from teachers' perspectives, in some selected primary schools of Nekemte town. So, to examine this impact, two sets of target population, teachers and principals were taken in the study. A questionnaire was administered to all teachers of the selected schools. Moreover, interview was conducted to school principals. The information obtained through questionnaire was analyzed using the procedure of descriptive and inferential statistics. The existence of statistically significant difference between the two compared groups in their mean score were computed using t-test (sex and experience) and statistically not significance between the two compared groups in their mean scores. In addition to this, the existence of significance difference among the groups of departments (language, social science, natural science and aesthetics) mean scores were computed using one-way ANOVA. Pearson moment correlation coefficient was also used to see the multicollinarity of the predictor variables and the criterion variable. In addition, proportion of the variance in formative assessment practice implementation explained by the predictor variables (awareness, attitude, experience, commitment and sex) the contribution of each independent variable to the dependent variable was analyzed by using multiple regression. From the regression analyses, the coefficient of determination (R2) indicates that about $14.4 \%$ of the variation accounted for in the dependent variable is due to the combined effect of the seven predictor variables. Conclusions and recommendations are made based on the results.
\end{abstract}

Keywords: Formative assessment; Factors, Practice; Experience; Attitude; Commitment; Primary schools

\section{Introduction}

Quality assessment is a very essential element in the provision of quality education. This is because assessment provides a foundation for making sound evaluative judgments about students' learning progress and about the effectiveness of the whole education system in general [1,2]. It is a general term that includes the full range of procedures used to gain information about students' learning and the information of value judgment concerning learning progress [3]. According to them, assessment is systematic processes that plays a significant role in effective teaching and begins with the identification of learning goals have been attained. Airasian [4] has also defined assessment as a process of collecting, interpreting and synthesizing information in decision making.

From the ideas stated above, one can infer that instruction requires formative assessment of students' progress as to benefit from learning, and that teachers have a great role in discharging this responsibility. Regarding this, formative assessment is a process used by teachers and students during instruction that provides feedback to adjust ongoing teaching and learning to improve student's achievement of intended instructional outcomes [5]. These days, advanced nation such as Australia, England, Spain and developing nations like Nigeria, Malawi, South Africa and others have incorporated formative assessment to their educational system [6,7]. Similarly, the Ethiopian Education and Training Policy gives due emphasis on the uses of FA as an effective means of instructional processes $[8,9]$. These documents argued that the committed practice of FA improves students' learning and among other things could alleviate the problem of grade repetition in elementary schools. However, research and personal observations of the researcher indicate that the implementation of FA at all levels of our education system is below the standard. Especially, in Nekemte Town Primary Schools.

\section{Statement of the Problem}

Assessment happens every day in classrooms. Therefore, nowadays, increasing attention is being given in education to the quality of classroom assessment, because more than any of 
its aspect's assessment plays a central role in determining the quality of education [4]. To this effect, formative assessment is both the means to ascertain the effectiveness of curriculum and is an indirect indicator of the teaching learning process [10]. Some countries of the world have passed laws and include provisions that make teachers accountable for the learning and development of students $[7,11]$.

Traditionally, in Ethiopia FA is understood as testing and measuring of the outcomes of learning. According to Black and William [12], FA is an essential component of the instructional process which enables the teacher to better use the "Assessment Feedback Correction" learning cycle that is missing from the time limited examinations. In addition to this, it helps teacher to collect the wide variety of information about their students' learning processes provides the basis for determining what they need to do next to move student learning forward. The use of formative assessment and remain to their old experiences [13].

Nekemte town primary schools were also related with the above idea. For that reason, problems like absence of enough awareness and teachers' failure to have positive attitude and commitment towards formative assessment were the major problems that hinder the implementation of FA. Beside this, teachers seem not committed to effectively implement FA in the classrooms. Thus, the problems mentioned above urged the researcher to conduct the study about the problem at hand.

Based on the above statement of the problem, the following basic questions are forwarded

a) Is there statistically a significance difference in the implementation of formative assessment between teachers due to their sex, work experience, age, and teacher's department to practice implementation of formative assessment?

b) Are there statistically significant relationship among sex, experience, age, department, awareness level, commitment and attitude towards the practice's implementation of formative assessment?

c) To what extent do sex, work experience, age, department, awareness, attitude and commitment influence the effectiveness of formative assessment implementation practice?

d) What are the factors that participants encountered in practices of formative assessment implementation?

\section{Objectives of the study}

The general objective of this study is to examine the factors that challenging the implementation of formative assessment in Nekemte primary schools from teachers' perspectives.

As specific objectives, it is aimed to

a) Investigate whether some variables namely sex, work experience, age and department significantly contribute to the differences in teacher's practices of FA implementation. b) To investigate the relationship between the predictor variables and the criterion variable.

c) To see the extent which the variables (as a group) relate to the effectiveness of FA practices.

d) Investigate the factors affecting of implementing formative assessment.

\section{Significance of the Study}

The findings of this study will be significant in:

a) Identifying the problems encountered in the implementation process of formative assessment and as a result makes aware policy makers and practitioners to the problems teachers are facing in implementing formative assessment at a classroom level.

b) It will indicate the extent, to which formative assessment is used, and the prevailing attitude, commitment, age, department, sex, work experience and awareness of teachers towards formative assessment.

c) Finally, it may also serve future researchers interested in classroom assessment as starting point.

\section{Delimitation of the study}

Although it was helpful to study the problem at larger area coverage and including all other factors, because of time and finance constraints and the researchers' interest as well, this study was delimited to make investigation on the factors affecting the implementation of formative assessment with a particular reference to teacher related variables (experience, age, department, sex, awareness, attitude and commitment) in the Nekemte primary schools. Specifically, the study is limited to investigating the level at which the Nekemte primary schools' teachers in the study area practice formative assessment and identifying the factors that call for stakeholders' attention.

\section{Literature review}

Many Scholars based on what they want to give more emphasis, have different views regarding educational assessment, some consider formative assessment more than summative assessment or vice versa. So, it is vital to briefly look at assessment in general in order to understand the concept of formative assessment and feedback. Assessment is defined as the process of gathering, interpreting, recording, and using information about the pupils" response to educational tasks [14]. It becomes a helpful and constructive tool when the information derived from it is used to adapt and modify the applied teaching and learning techniques [12]. On the other hand, assessment refers to the full range of information gathered and synthesized by teachers for making decisions about their students. Information gathered through both informal (observation and verbal exchange) and formal (homework, tests, quizzes and etc) [15]. From the above scholar's definitions of assessment, it seems that assessment is for decision making but this brings the notion that there is no conceptual 
difference between assessment and evaluation. While, evaluation of learners is the process of making a judgment about the quality of a learner's performance using the information gathered during an assessment. It further adds; action is what you do as the result of your assessment of learners and evaluation of their assessment information [15].

Historically speaking, assessment can have a more noticeable influence on students" behavior and performance than teaching does [16]. Assessment is still the most influential factor in formal education and, if not approached properly, may subvert the positive aspects of both the teaching and learning process. Although tests and examinations are considered as one way of assessing, assessment does not mean testing. There is an obvious distinction between assessing and testing students" performance. The purposes of tests or examinations determine clearly whether they are being used for assessment or testing [17]. They are "testing" if they only provide students with marks, the final judgment, without any useful feedback of what they have (or have not) mastered. On the contrary, they are "assessments" when they aim to identify what students need to do in order to enhance their performance in the future.

In contrast to testing, assessment with the provision of feedback (as its main distinctive feature) has an enormous advantage since students are informed about the continuous development in their achievement. Ainsworth [18] alludes to the dissimilarity between tests and assessments by arguing that the latter can: a) motivate students to be more engaged in learning, b) help students develop positive attitudes toward a subject, and c) give students feedback about what they know and can do. It is instructive to recognize the purposes of assessments before addressing assessment types. Kellough [19] have characterized six purposes of assessment:

a) To assist student learning.

b) To identify students" strengths and weaknesses.

c) To assess the effectiveness of a particular instructional strategy.

d) To assess and improve the effectiveness of curriculum programs.

e) To assess and improve teaching effectiveness.

f) To provide data that assist in decision making.

In addition, it is crucial to establish clear principles that may successfully guide the implementation of assessments. The following six principles have been adapted from Pausch \& Popp [20] who also stress the significance of grounding assessments" purposes on rational principles. These principles are:

a) The assessment of student learning begins with educational values.

b) Assessment is most effective when it reflects an understanding of learning as multidimensional, integrated, and revealed in performance over time.

c) Assessment works best when the programs it seeks to improve have clear, explicitly stated purposes.

d) Assessment requires attention to outcomes but also and equally to the experiences that lead to those outcomes.

e) Assessment works best when it is ongoing, not episodic.

f) Assessment is most likely to lead to improvement when it is part of a largest of conditions that promote change.

In past decades, teachers would design a unit of study that would typically include objectives, teaching strategies, and resources. The student's mark on this test or exam was taken as the indicator of his or her understanding of the topic. In 1998, Black \& Wiliam [12] produced a review that highlighted that students who learn in a formative way achieve significantly better than matched control groups receiving normal teaching. Formative assessment occurs throughout the learning process. It is designed to make each student's understanding visible, so that teachers can decide what they can do to help students progress. Students learn in individual and personal ways, yet, at the same time, there are predictable patterns of connections and preconceptions that some students may experience as they move along the continuum from emergent to proficient [21].

In formative assessment, teachers use assessment as an investigative tool to find out as much as they can about what their students know and can do, and what confusions, preconceptions, or gaps they might have. The wide variety of information that teachers collect about their students' learning processes provides the basis for determining what they need to do next to move student learning forward. It provides the basis for providing descriptive feedback for students and deciding on groupings, instructional strategies, and resources. In formative assessment, teachers use assessment evidences to monitor students learning progress and inform their teaching. This form of assessment is designed to provide diagnostic information to teachers about students' prior knowledge and formative information about the effects of their instruction on student learning [21]. So, the roles of teacher in formative assessments are:

a) Aligning instruction with the targeted outcomes.

b) Identifying particular learning needs of students or groups.

c) Selecting and adapting materials and resources.

d) Creating differentiated teaching strategies and learning opportunities for helping individual students move forward in their learning.

e) Providing immediate feedback and direction to students.

f) Enhance students' motivation and commitment to learning. 
g) Help students identify their strengths and weaknesses and target areas that need work.

h) help facility recognize where students are struggling and address problems immediately.

i) It creates a competitive learning environment and boosts students" attitudes toward learning since its primary focus is to help students understand the level of learning they have achieved [22].

When teachers commit to learning as the focus of assessment, they change the classroom culture to one of student success. They make visible what students believe to be true and use that information to help students move forward in manageable, efficient, and respectful ways. Formative assessments are generally low stakes, which means that they have low or no point value. Examples of formative assessments include asking students to: draw a concept map in class to represent their understanding of a topic, submit one or two sentences identifying the main point of a lecture and turn in a research proposal for early feedback [22].

Research findings on whether or not teachers vary in their classroom practice with the variation in their teaching experience present mixed findings. For instance, Girma [23] contended that teachers previous professional experience poses problems that are more intractable, because more experienced may have established their own pattern of behavior in classroom settings than less experienced ones. In other words, the more the teacher is professionally experienced, the less likely he/she is willing to exert considerable effort to implement pedagogical innovations like assessment. Research reports by many scholars also reported that increments in experience were associated with decline in obligation to classroom practices. That is, teachers with more teaching experience were slightly less devoted than did teachers with less experience $[24,25]$.

Girma [23] argued that the teacher is the most significant factor in determining the success of new pedagogical innovations. This is partly, because teachers' implementation of that improvement is dependent up on teachers' attitude towards the originality, knowledge about the advance, and their level of commitment to implement it. Teachers' attitude towards pedagogical innovations such as FA can be one of the causes of the discrepancy between prescribed theory and classroom practice. In another words, the match or mismatch between teachers' beliefs and that innovation influences its implementation in the actual classroom practice. Because teachers' reaction is to change it's determined by this congruence between their beliefs and attitudes combined and that innovation. On the other hand, Alausa [26] found that had it not been the conceptual gap on FA, teachers everywhere are willing enough to embrace new ideas about assessment. Stated simply, it is to mean that teachers have already developed positive attitude towards FA, but they have lack of understanding on its conceptual frame works.
The second teacher related constraints that influence teachers' effective implementation of FA is their knowledge about FA and its practical implications (i.e. given positive attitude by teachers towards an innovation, teachers' awareness about that pedagogical innovation may be a source of rejection of the innovation. Regarding this, Girma [23] has the following to say: Teachers may favor a change and yet fail to implement it effectively if they do not have a clear understanding of the theoretical under pinning and practical application of the change. Similarly, in the literature it is indicated that teachers lack knowledge about the conceptual framework of FA or about the special value that quality assessment has for improving quality of education [26-28].

The other teacher related potential factor hampering proper implementation of FA is teachers' lack of commitment. Literature indicates that successful implementation of FA requires teachers to provide variety of assessment tools [26]. More specifically, assessment demands teachers to prepare effective plan, act accordingly and continuously evaluate how learning is going on. The procedure includes provision of assignments and tests, supplementary assessment, providing immediate and constructive feedback, calculation of final marks for all subjects, and reporting to parents how pupils are progressing $[7,26]$. It is obvious that these activities mean more work to the teacher, more demand on his /her time, and more responsibility [29,30], which in turn requires teachers' commitment to invest inputs assessment implementation demand.

The school situation may facilitate or hamper FA implementation in the teaching learning process. The school context may be explained by; Pupil-teacher ratio, available school facilities (like laboratory, library, and classroom facilities), teaching materials, administrative supports, pupils' competence, and parents' involvement. Many researchers have described that large class size (unfair pupil-teacher ratio) is an important challenge to implement assessment, because it prohibits teachers to follow-up pupils in their homework's and assignments [29-32]. The underlying reason is that in classrooms where the number of students is large, teachers may consider the provision of feedback and follow up activities are difficult [31-33].

\section{Methods}

\section{Study design}

A descriptive survey method was designed to be used for this study. Since the purpose of this study was the factors that affect the implementation of formative assessment in some selected Nekemte primary schools, and it is assumed that the problems were approached using descriptive method. This method is an appropriate research method to get a description of current status of a problem by examining and describing the major problems facing primary schools.

\section{Subject of the study}

The samples of the population of this study were teachers and principals in three selected primary schools in Nekemte town. 
In these primary schools there were a total population of 123 teachers, and 3 principals.

Table 1: Sample population of the study.

\begin{tabular}{|c|c|c|c|c|c|c|c|}
\hline \multirow{2}{*}{ No } & & \multicolumn{3}{|c|}{ Population } & \multicolumn{3}{c|}{ Sample Size } \\
\cline { 3 - 8 } & M & F & T & M & F & T \\
\hline 1 & School Principals & 3 & - & 3 & 3 & - & 3 \\
\hline 2 & $\begin{array}{c}\text { Primary school } \\
\text { teachers }\end{array}$ & 22 & 101 & 123 & 22 & 101 & 123 \\
\hline \multicolumn{2}{|c|}{ Total } & 25 & 101 & 126 & 25 & 101 & 126 \\
\hline
\end{tabular}

\section{Samples and sampling techniques}

Sampling is closely linked to the external validity or generalizability of the findings in an enquiry; the extent to which what we have found in a particular situation at a particular time applies more generally [34]. So, the sample population of the study was shown under the following in (Table 1).

The sample population was obtained from the three primary school teachers. Concerning the sampling techniques teachers were selected using Purposive sampling technique. Because of the number of the population was small and manageable. Due to this, the researcher was interested to use the whole population as a sample of the study. The school director (Principals) was also selected by purposive sampling technique.

\section{Instrument of data collection}

In order to achieve the objectives, the instruments used to collect data for the study was questionnaires and interview.

\section{Questionnaires}

These instruments are the primary instruments to collect data from the target population. The researcher developed the questionnaire based on the statement of the problem and review of related literature. The prepared questionnaires were administered to primary school teachers

\section{Interview}

Like the questionnaires, the interview was developed based on the statement of the problem and review of related literature. Moreover, it was used to support information gathered through questionnaires since it has occupied an important place in descriptive educational research. The prepared interviews were administered to primary school principals.

\section{Procedure of Data Collection}

The instrument was constructed, piloted and collected by the researcher directly and analyzed.

\section{Method of data analysis}

The data obtained from the closed ended questionnaire was tabulated and analyzed quantitatively. This is through percentage, mean, standard deviation, t-test, one-way ANOVA, correlation and multiple regressions. The result of the data was analyzed by SPSS-version-20 and for the data obtained from open ended and interviews was analyzed qualitatively.

\section{Result and Discussion}

\section{Analysis of quantitative data}

In this section, the results obtained from questionnaires for teachers, and interview for principals were analyzed.

\section{Analyses of independent t-test on teachers' sex to implement formative assessment}

The analysis on the sex through the independent t-test of (Table 2) above revealed that teachers with different sex did not significantly differ in their practices of formative assessment implementation. This indicates that, sex of teachers does not affect formative assessment practices in the schools under the study area. This finding is consistent with the findings of Ajuonuma [35] that sex does not affect the formative assessment practices in Nigerian universities.

Table 2: Shows that the comparison of teachers' sex to implement formative assessment. Note: Equal variance assumed $=0.399 \alpha=.05$.

\begin{tabular}{|c|c|c|c|c|c|c|}
\hline Sex & N & M & SD & Df & T & P-Value \\
\cline { 1 - 4 } Female & 101 & 0.8911 & 0.799 & & & \multirow{2}{*}{0.846} \\
\hline Male & 22 & .0455 & 0.653 & 121 & 0.399 \\
\hline
\end{tabular}

\section{Analyses of independent t-test on teachers' work experience}

An independent t-test was conducted to compare the mean scores of teachers' work experience of the practices of formative assessment between low experiences and high experiences on implementation of formative assessment as indicated in the (Table 3 ). The difference between the mean scores of the two groups is found to be statistically not significant at .05 levels. This implies teachers with varying experience did not significantly differ in their usage of the formative assessment approach to assess students' learning progress. Adebowale et al. [36] reported a similar finding; they found that teachers' teaching experience did not significantly contribute to the variation in their implementation of formative assessment. In addition, this finding is in agreement with the previous studies [23].

Table 3: Analysis of Independent t-test on teachers work experience to implement formative assessment. Note: Equal variance assumed $=0.096$ $\alpha=.05$.

\begin{tabular}{|c|c|c|c|c|c|c|}
\hline Experience & $\mathbf{N}$ & M & SD & Df & T & P-Value \\
\hline $0-6$ years & 21 & 1.073 & 0.788 & \multirow{2}{*}{121} & -0.108 & 0.096 \\
\hline 7 years and above & 102 & 1.086 & 0.552 & & \\
\hline
\end{tabular}




\section{Annals of Social Sciences \& Management studies}

Analyses of one-way ANOVA teacher's department to formative assessment implementation practices

(Table 4) As can be seen from (Table 5), teachers were significantly differing in their practices of formative assessment with the difference in their department $[F(3,120)=7.179, p<.05]$ [Language, Social science, Natural science and Aesthetics]. The mean score obtained by participants who were teaching natural science subjects was the lowest $(M=.742)$ when compared with those who were teaching Language $(M=1.4)$, social science ( $M$ =1.07) and Aesthetics ( $M=1.042)$. To identify participants of which category significantly differ, a post hoc tests also called post hoc comparison was run (Tukey).

Post-hoc comparison using Tukey HSD indicated that the mean score of language ( $M=1.4, \mathrm{SD}=.496)$ was significantly different from the Natural science $(\mathrm{M}=.742, \mathrm{SD}=.444)$ with a mean difference of .6580 and the mean scores of social science (M $=1.07, \mathrm{SD}=.813)$ was significantly different from the mean score of natural 8science $(\mathrm{M}=.742, \mathrm{SD}=.444)$ with a mean difference of 0.328 . But the mean score for aesthetics $(\mathrm{M}=1.042, \mathrm{SD}=.624) \mathrm{did}$ not have mean difference with any of the department.

The analysis employed ANOVA (Table 4) and subsequent post hoc comparison (Table 5) have clearly indicated that participants who were teaching Language and/or Social Science subjects were found significantly different from those who were teaching Natural Science and/or aesthetics as regards formative assessment implementation. Further analysis of post hoc comparison revealed that mean score of language and Social Science teachers were also significantly higher than the mean score of Natural Science and aesthetics (Table 6).

Table 4: The mean and Standard Deviation for Teachers Department Score.

\begin{tabular}{|c|c|c|c|}
\hline Subject & N & M & SD \\
\hline Language & 40 & 1.4 & .496 \\
\hline Natural Science & 31 & .742 & .444 \\
\hline Social Science & 28 & 1.07 & .813 \\
\hline Aesthetics & 24 & 1.042 & .624 \\
\hline Total & 123 & & \\
\hline
\end{tabular}

Table 5: ANOVA Summary for Teachers Department to Formative Assessment Implementation Practices.

\begin{tabular}{|c|c|c|c|c|c|}
\hline & Sum of Squares & Df & Mean Square & F & Sig \\
\hline \multirow{2}{*}{ Between groups } & 7.665 & 3 & 2.555 & 7.179 & \\
\hline Within groups & 42.351 & 119 & 0.00 & \\
\hline Total & 50.016 & 122 & & & \\
\end{tabular}

Table 6: Post-Hoc Tests for Different Department Categories (Tukey). *pair of groups significantly different $(p<.05)$.

\begin{tabular}{|c|c|c|c|}
\hline \multirow{4}{*}{ (I) Stream } & (J) Department & Mean Difference (I-J) & Sig. \\
\hline \multirow{3}{*}{ Aesthetics } & Social Science & -.02976 & .998 \\
\cline { 2 - 4 } & Language & -.35833 & .098 \\
\cline { 2 - 4 } & Natural Science & .29973 & .256 \\
\hline \multirow{3}{*}{ Social Science } & Aesthetics & .02976 & .998 \\
\cline { 2 - 4 } & Language & -.32857 & .120 \\
\cline { 2 - 4 } & Natural Science & $.32949 *$ & .098 \\
\cline { 2 - 4 } & Aesthetics & .35833 & .120 \\
\cline { 2 - 4 } & Social Science & .32857 & .000 \\
\hline \multirow{3}{*}{ Language } & Natural Science & $.65806 *$ & .256 \\
\cline { 2 - 4 } & Aesthetics & -.29973 & .153 \\
\cline { 2 - 4 } & Social Science & -.32949 & .000 \\
\hline
\end{tabular}

This difference might be found its root in the way curriculum materials were organized in the subjects considered. It was found that Language and Social science teachers mark on students' exercise books more frequently than Natural science and aesthetics teachers. Thus, it is certain that the organization of curriculum material helped Language and Social science teachers implementing formative assessment through homework, class work, assignment, etc. 
Proportion of the variance in formative assessment practices that is explained by all the independent variables

In this section, in the process of multiple regression analysis, the association between the dependent variable and the predictor variables has been estimated using Pearson correlation coefficient. The results of the analysis made are presented in (Table 7) below.

As a result, shown in (Table 7) above, teachers' awareness, attitude, and commitment are correlated positively and significantly with formative assessment practices $(\mathrm{r}=.148, .126$,

Table 7: The association between the dependent variable and the predictor variables. Note: ${ }^{* *}$ Correlation is significant at the .01 level, ${ }^{*} \mathrm{Correlation}$ is significant at the .05 level.

\begin{tabular}{|c|c|c|c|c|c|c|c|c|}
\hline Variables & Sex & Department & Experience & Age & Awareness & Attitude & Commitment & $\begin{array}{c}\text { Formative Assessment Prac- } \\
\text { tice }\end{array}$ \\
\hline Sex & 1 & & & & & & & \\
\hline Department & $.719 * *$ & 1 & & & & & & \\
\hline Experience & $.387^{* *}$ & $.700^{* *}$ & 1 & & & & & \\
\hline Age & $.654^{* *}$ & $.906^{* *}$ & $.614^{* *}$ & 1 & & & & \\
\hline Awareness & $.734^{* *}$ & $.672^{* *}$ & $.551^{* *}$ & $.666^{* *}$ & 1 & & & \\
\hline Attitude & $-.058^{*}$ & $-.273^{* *}$ & .066 & $-.273^{* *}$ & .030 & 1 & & \\
\hline $\begin{array}{l}\text { Commit- } \\
\text { ment }\end{array}$ & .056 & .162 & .162 & $.215^{* *}$ & $.180^{* *}$ & -.030 & 1 & \\
\hline $\begin{array}{c}\text { Formative } \\
\text { Assessment } \\
\text { practice }\end{array}$ & .032 & -.096 & .041 & $-.132 *$ & $.148^{*}$ & $.126^{*}$ & $.106^{*}$ & 1 \\
\hline
\end{tabular}

In order to identify a more predictive independent variable(s) that brought significant variation (contribution) on implementation of formative assessment, a regression analysis was used on the selected predictor variables. Hence, formative assessment practice was taken as a dependent variable to be seen in relation to the independent variables impact on implementation of formative assessment. In the foregoing correlation analysis, the association between the dependent variable and seven independent variables has been estimated. In effect department and age patterns showed statistically not-significant relationship with practices of formative assessment implementation in the present study. The remaining variables (sex, experience, awareness, attitude and, commitment) are significantly associated with formative assessment practice implementation. It is of interest in this study to further distinguish the combined effects of these independent variables on the dependent variable using multiple regression models. A regression method brings out the relationships between variables whose relation is imperfect. Thus, in the regression estimation for dependent variable, seven predictor variables listed above under correlation (Table 7) which are expected to affect practices of formative assessment implementation were included in the model.

(Table 8) depicts the relationship between practices of formative assessment implementation and various predictor variables were estimated. The combination of the predictor and .106, respectively) at .05 level. But department and age were negatively correlate (-.096 and -.132) with the dependent variable. The remaining variables like sex and teachers' work experience showed not statistically significant relationship with the criterion variable. Tabachnick \& Fidell [37] suggest that including two independent variables with absolute value of a bivariate correlation of .70 or more in the same analysis violates multi-colinearity assumption. In line with this, in the study the maximum correlation is 906 (Table 7), which is greater than .70; therefore, all variables were taken. variables as estimated from the coefficient of multiple $R(.375)$ and $\mathrm{F}$ test i.e. the practice of formative assessment implementation variation with an ANOVA F-ratio of $F(7,115)=2.693, p<.05$ was statistically significant. The coefficient of determination R2 indicates that about $14.1 \%$ of the variation accounted for in the dependent variable is due to the combined effect of the seven mentioned predictor variables. The goodness of the model also shows that, the adjusted R2 (unbiased estimate of the variance) was .089 . This reveals that, about $8.9 \%$ of the variation for the dependent variable was due to the combined effect of the mentioned predictor variables included in the model.

From the total of seven predictor variables specified for practices formative assessment of implementation, the measure of relative importance of each variable (shown under "Beta" column) revealed that, five variables were found to be best describing the variability of formative assessment practices in the study area and statistically significant at .05 level. These variables are sex, experience, awareness, attitude and commitment. Moreover, (Table 8) depicts that experience was found to have the highest (the maximum Beta coefficient $=.366$ ) significant positive effect in predicting formative assessment practices as rated by the respondents and followed by commitment, attitude, sex and awareness. The "beta coefficient" for the remaining predictor department and age did not show significant effects on practices of FA implementation at .05 levels. Therefore, these variables 
might not be significantly contributing to the regression equation when used in combination with other variables. The sign of the regression variables was also not similar with the predetermined

Table 8: Summary of Multiple Regression Analysis. hypothesis made. The negative sign of beta coefficient for department and age shows that when predictor variables increase the criterion variable decreases.

\begin{tabular}{|c|c|c|c|c|c|}
\hline \multirow{2}{*}{$\begin{array}{l}\text { Independent } \\
\text { Variables }\end{array}$} & \multicolumn{2}{|c|}{ Unstandardized Coefficients } & \multirow{2}{*}{$\begin{array}{c}\text { Standardized Coefficients } \\
\beta\end{array}$} & \multirow{2}{*}{$\mathbf{t}$} & \multirow{2}{*}{ Sig. } \\
\hline & B & Std. Error & & & \\
\hline FA Practice & 1.184 & .186 & & 6.378 & .000 \\
\hline Sex & .548 & .264 & .129 & 2.072 & .041 \\
\hline Department & -.267 & .163 & -.444 & -1.634 & .105 \\
\hline Experience & .481 & .189 & .366 & $2.543^{*}$ & .019 \\
\hline Age & -.245 & .152 & -.343 & -1.613 & .110 \\
\hline Awareness & .101 & .132 & .113 & $.767^{*}$ & .045 \\
\hline Attitude & .106 & .045 & .245 & $2.369^{*}$ & .019 \\
\hline Commitment & .081 & .050 & .246 & $1.622^{*}$ & .017 \\
\hline
\end{tabular}

Note: * the effect is significant at the $.05 . \alpha=.05$

$\mathrm{R}=.375$

$$
\mathrm{R}^{2}=.141
$$

Adjusted R square $=.089$

$$
\text { S. error }=.61
$$

$F(7,115)=2.693$

$$
\mathrm{P}<.001
$$

\section{Qualitative data analysis}

The results from interview questions displayed that, formative assessment practices in the research were found far from the students. The results assured that, the majority of the participants were do not use appropriate time for assessment related tasks, assess their students less frequently, limited the scope of formative assessment to its final component dominantly through tests and exams, did not provide remedial and enrichment activities sufficiently, and did not make students' learning improvement.

In order to meet the learning needs of each student, the various assessment methods must be incorporated in the lesson plan. The use of assessment during teaching learning on going as a major technique of evaluation in active learning at secondary school level is a policy consideration since 1994 in Ethiopia. Therefore, teachers are supposed to present many things to teach their students. In such activity the teacher is a coach and facilitator to guide the process and to give regularly and timely assessment in order to evaluate students' progress in learning. However, depending on the nature of the subject, the assessment techniques to be used vary from one subject to the other even in the same subject between different contents or the same teachers on the same contents. In support of this, Gary et al. [38] on their part argues that there are a number of types of assessments which can be appropriate for different assessment purposes.

\section{Factors affecting formative assessment practices}

From the interview questions, on what problems primary school teachers faced in formative assessment practices reveals that, almost all of them responded that, formative assessment practices are difficult and unmanageable under their school contexts. Most of them were, number of students in the classroom,

teachers' additional work (department head, unit leader, director, different members of committee), teachers work load (overloaded for example, 20-38 periods), large class size (60-97 students in one class), teachers' unsuitability, lack of support from the leaders(Directors, school supervisors, Nekemte town Education Bureau and others), incompatibility of classroom, lack of different teaching materials, lack of time, assessment biased and others.

\section{Conclusion and Recommendations}

\section{Based on the main findings of the study, the following conclusions were drawn}

a) Based on the independent sample t-test observed between the male and female group of teachers, one may conclude that there was no difference in practicing of formative assessment implementation among teachers.

b) Similarly, results obtained from the teachers' department, teachers who teach Language and social science subjects were more practicing formative assessment implementation than teachers who teach natural science and aesthetics subjects.

c) Regarding the teachers' work experiences, there was no statistically significant difference teacher's experiences in formative assessment practice implementation.

d) The proportion of the variance in formative assessment practices that were independent accounted together (awareness, attitude, sex, department and commitment) is $\mathrm{R} 2=14.1 \%$. Therefore, these variables are essential for the implementation of formative assessment.

e) The major factors that hinder the practices of formative assessment implementation were number of students, teachers' unsuitability, large class size, lack of administrative 
support, complexity of assessment tools, lack of time, unequal contribution of group members in group works, etc.

\section{Based on the major finding of the study, the following recommendations were forwarded}

a) To raise the level of awareness of teachers towards formative assessment and its implementation and thereby to positively influence the attitude of teachers towards the system, intensive trainings on the concepts and roles of assessment (especially formative assessment). Example, on the job trainings, workshops, seminars and in-service programs. In addition to this, the Continues Professional Development (CPD) program in primary schools should address all the teachers with the knowledge and skills of assessment.

b) To ensure effective formative assessment practices in the schools or in the classrooms, the concerned bodies (Teachers, Students, Students' families, School Principals, Nekemte town education bureau, Oromia Education Bureau and others) should work on it,

c) Lack of required educational resources and facilities were the main hindering factors in the implementation of formative assessment. Therefore, Nekemte town Education Bureau should be allocating it timely.

d) Finally, it was also recommended that, further research should be carried out by using more other methods, improving instruments used in the present study and including other relevant variables.

\section{References}

1. McMillan JM (2004) Fundamental assessment principles for teachers and school administrators: In Caulley KM, Linder F, McMillan H (eds) Educational psychology. McGraw-Hill/Dushkin, A division of McGrawHill Companies. USA.

2. USAID/BEP (2006b) A concise manual for developing and implementing continuous assessment in teacher education institutions and primary schools of Ethiopia: Addis. Ethiopia.

3. Linn, Robert L, Gronlund E Norman (2005) Measurement and assessment in teaching. ( $8^{\text {th }}$ edn), India; Baba Barkha Nath Printers. India.

4. Airasian PW (1991) Classroom assessment. McGraw- Hill, New York.

5. FAST SCASS (2008) Attributes of effective formative assessment. Paper prepared for the Formative Assessment for Teachers and Students State Collaborative on Assessment and Student Standards of the Council of Chief State School Officers. Washington, DC: Council of Chief State School Officers. USA.

6. Little A, Wolf A (1996) Assessment in transition: Learning, mentoring and selection, international perspective. New York: Elsevier Science. Ltd. Maid. American Psychologist. New York.

7. Njabili AF (1999) Practical guide for classroom measurement and testing: The basic essentials ( $3^{\text {rd }}$ edn), Dares Selam: Muture Publisher. East Africa.

8. MOE (2002) The Educational and training policy and its implementation: Addis Ababa: MOE. Ethiopia.

9. TGE (1994) Education and training policy: Addis Ababa: Educational materials production and Distribution Agency. Ethiopia.
10. Girma Abadi (2001) Evaluation training in the health science faculty of Dilla College from the perspective curriculum, teaching methodology, student evaluation. IER FLAMBEAU 9(1).

11. Gronlund NE (1981) Measurement and evaluation in teaching. $\left(4^{\text {th }}\right.$ edn), McMillan Publishing Co, Inc. New York.

12. Black P, Wiliam D (2009) Developing the theory of formative assessment. Educational Assessment Evaluation and Accountability 21: 5 .

13. ICDR, MOE (2002) Educational wastage in five regions of Ethiopia Educational Research Panel, Curriculum Evaluation and Educational Research Coordination: Addis Ababa. Ethiopia.

14. Lambert D, Lines D (2000) Understanding assessment: Purposes, perceptions, practice. London, Routledge Falmer. New York.

15. Arends R (1997) Classroom instruction and management: McGrawHill, Inc. New York.

16. Miller CMI, Parlett M (1974) Up to the Mark: a study of the examination game. Guildford: Society for Research into Higher Education. England.

17. Knight P (2001) A briefing on key concepts: Formative and summative, criterion and norm-referenced assessment, assessment series No.7. York: LTSN, New York.

18. Ainsworth L (2006) Common formative assessments: How to connect standard based instruction and assessment. Thousand Oaks, California: Crown Press. California.

19. Kellough RD, Kellough NG (1999) Secondary school teaching: A Guide to methods and resources.

20. Pausch LM, Popp MP (1997) Assessment of information literacy: Lessons from the higher education assessment movement.

21. Black P, William D (1998b) Assessment and classroom learning: Assessment in Education 5(1): 7-74.

22. Irons A (2008) Enhancing learning through formative assessment and feedback. London; New York: Routledge. New York.

23. Girma Gezahegn (2006) A study of factors influences teacher's implementation of curriculum innovation: A lesson for teacher educators.

24. Riley RW, Smith M, Forgione PD (1997) Teacher professionalization and teacher commitment: A multi-level analysis. National centre for educational statistics. USA.

25. Henkin AB, Holliman SL (2008) Urban Teacher Commitment: Exploring Associations with Organizational Conflict, Support for Innovation, and Participation 44(2): 160-180.

26. Alausa YA (2003) Continuous assessment in our school: Advantage and problems.

27. Mkony CA, Mbembati NA, Hamudu NA, Pallangyo K (2007) Introduction of regular formative assessment to enhance learning for clinical students at Muhimbili University College, Tanzania. Education for Health 20(3): 129.

28. Obioma G (2008) Continuous assessment practices of primary and junior secondary school teachers in Nigeria. Nigeria.

29. Derebssa Dufera (2001) Perspective and challenges of achieving the millennium development educational goals in Ethiopia: Where does Ethiopia Stand on EFA Goals? The Ethiopian Journal of Education 26(2): $25-56$

30. Miske S, Schmidt S, Santhe E (2003) Findings from an exploratory study of teachers' beliefs and practices about pupils' assessment in Malawi, improving educational quality (IEQ) Project: The University of Pittsburgh: Juarret and Associates, Inc. USA.

31. USAID/BEP (2007) Ethiopian second national learning assessment of grade students: Addis Ababa (unpublished). Ethiopia. 


\section{Annals of Social Sciences \& Management studies}

32. Mulu Nega (2005) The quantity Vs quality dilemma in the expansion of higher education in Ethiopia: Implications for further directions. In: Daniel et al. (Eds.), Proceedings of the national conferences held in SGS 21-22 October 2005 on where Ethiopia's higher education should be going and how might it change to meet the country's development needs. Ethiopia.

33. Yonas Adaye (2003) Primary school teachers' perceived difficulties in implementing in innovative ELT methodologies in Ethiopian context: IER Flambeau 11 (1): 23-25.

34. Robson C (199S) Real World Research. Oxford: Blackwel!

35. Ajuonuma JO (2006) Competences possessed by teachers in the assessment of students in the universal basic education Program. An
Annual National Conference of the department of paper presented at the $2^{\text {nd }}$ Educational Foundations, Enugu State University.

36. Adebowale DF, Alao KA (2008) Continuous assessment policy implementation in selected local government areas of Ondo State (Nigeria): Implications for successful implementation of the UBE program, KEJP Journal of educational.

37. Tabachnick BG, Fidell LS (2001) Using multivariate statistics. ( $4^{\text {th }}$ edn), New York: HarperCollins.

38. Gary C (2004) An assessment framework for the community college. measuring student learning and achievement as a means of demonstrating institutional effectiveness 1:2-35. 